\title{
Assessment feedback in higher education: preliminary results in a course of strategic management
}

\author{
Montserrat Boronat-Navarro*, Beatriz Forés*, Alba Puig-Denia*
}

Universitat Jaume I

\begin{abstract}
Assessment feedback improves the process of learning by giving students the possibility to analyze their own learning process and the points in which they fail in the activities. Nevertheless, their application in the higher educational environment could have some difficulties due to the number of students in each group. The aim of this project is to analyze the assessment feedback concept and its importance in teaching strategic management subjects. The study presents descriptive results of the perceptions of the students in a group in which feedback is included as a usual activity in the development of the subject. Students positively evaluate the feedback provided by the teacher, and also their academic marks are positive.
\end{abstract}

Keywords: assessment feedback; higher education; strategic management

\section{Introduction and background}

Assessment feedback in higher education has been theoretically and empirically studied due to its potential to enhance the student's learnig process. As Evans (2013: 71) pointed, the concept of assessment feedback "includes all feedback exchanges generated within assessment design [...] in the learning context". Feedback aims to improve the level of performance in learning by reducing the gap between the actual level of performance and the learning goal (Draper, 2009; Lizzio and Wilson, 2008; Wiliam, 2011).

Although its potential benefits seem to be clear, its application in the higher educational environment could have some difficulties due to the number of students in each group. It could be a reason for the lack of studies that empirically analyze feedback strategies in the Spanish higher education environment, and specifically, in management subjects in which this project focuses on. Therefore, there is a challenge the application of feedback assessment and the improvement of the feedback quality in this context.

Therefore, as teachers in strategic management subjects, we included assessment feedback in one group of students in the third year of the Degree in Business Administration, in the first semester of this academic course. We present in this study preliminary descriptive results from a survey that analyzes students' perception of the feedback activities introduced in the classroom. The objective of the paper is to analyze the assessment feedback concept and their importance in teaching strategic management subjects.

The next section defines the concept and types of assessment feedback and explains the importance of this activity in subjects related with strategic management in higher education. In the methods section, the main characteristics of the educational project are described. Then, we present some descriptive results of the survey completed by the students related to their satisfaction with the activities that include feedback from the teacher and comment briefly academic marks of the group. Finally, we analyze the main conclusions. 


\section{Background}

\section{Assessment feedback}

There are different types of feedback depending on their purpose (Hattie and Timperley, 2007). The first one, task feedback, clarifies aspects of the task carried out to reinforce the learning. Process feedback, as a second type, is centred on how the student addresses a specific task. The third one, self-regulation feedback evaluates the strategies the student uses. Finally, self-feedback analyzes personal attributes of the student in the process. In this study, we focus on the first one, task feedback, although the feedback process in a learning environment could be difficult to differentiate because this process includes also some aspects of the other types pointed out. Furthermore, the different objectives of feedback must be considerate as integrated dimensions of feedback (Evans, 2013). It includes motivational, reinforcement and informational aspects (Nelson and Schunn, 2009).

Distinction between the cognitivist and socio-constructivist perspectives of feedback is also highlighted in the literature. Whereas the first one emphasizes feedback as corrective information provided by an expert, in the last one feedback is a facilitative process to help students. Nevertheless, both perspectives are reinforcing each other rather than being exclusive points of view (Evans, 2013). By using feedback as a corrective tool we should also provide students a better understanding on how the task must be carried out.

\section{Management studies}

Strategic management subjects have some characteristics that make more complex the process of teaching and learning. As a social science, it analyzes unstructured and complex problems, the high diversity of the object under study and the influence of the environment (markets, competitors, economy, laws, technology, etc.). The importance of social factors and the ambiguous relationships among variables, together with the difficulty in measuring the variables involved, and the multiple approaches and paradigms, gives more complexity to the subjects related to strategic management.

Due to this ambiguity in the aspects analysed by strategic management subjects, students must be involved in continuously searching and analysing qualitative and quantitative information to solve practical cases related to real problems. The different variables involved in determining the success or failure of organisations together with the importance of social and behavioural factors, make more difficult the learningteaching process.

Strategic management subjects require that teachers are able to provide the students a wide range of capabilities that allow them to perform their future job. Learning based on a constructivist view puts its strength on the knowledge building in an autonomous way by the students who adopts an active role in the process. Teacher acts a mediator agent between the learning and the student. The methodology in this kind of learning includes different strategies such as classroom debate, group debates, working in teams, tutorials, etc., which stimulate the participation of the students (Slavin, 1990). Where the number of students is high, to take benefit of the advantages that these methodologies offer it is possible to combine them in different moments of the learning process development. 
In this context, the importance of assessment feedback is clear. In this type of subject, the process of analyzing a specific problem, case or activity, is even more important than the solution achieved. Therefore, feedback should provide benefits to the process of learning in the management area.

\section{Methods}

In this section we explain the project carried out in the third course of a Degree in Business Administration in Jaume I University (Castellón, Spain) in a subject related to strategic management. In this subject, the syllabus includes all the aspects of the process of analyzing and formulating business strategies.

In the theoretical sessions of the subject, individual or group activities are proposed to students to learn and to analyze in depth some aspects of the syllabus that are also explained by the teacher. Students write a brief report of the activity (one page) and the teacher helps to solve doubts, to focus the question and the answer, etc. This fact also constitutes an activity of feedback, in the sense that the teacher guides students in how they must approach to the activity and in the comprehension of doubts or problems they find to answer the question. In following sessions, the teacher also explains the main problems observed in the activity and returns the correction of the activity.

The methodology in the practical part of the subject is based on teamwork in tutorial sessions. Considering the objective of bringing reality to students, the sessions are designed to analyse the process of strategic management in a real firm they select. Students must prepare a final project based on the firm and the teacher should guide the development of this project in tutorial sessions. The assessment feedback is also carried out in these sessions, because all of them are focused on guiding the project, solving doubts, etc.

Furthermore, the second part of the syllabus includes typologies of strategies, their application, advantages and disadvantages. Teams in tutorial sessions must also analyze strategies and their applicability to their firm. Then, they must explain and defend in theoretical sessions one strategy to the other teams. The teacher selects the appropriate strategy to analyze in each firm and each group must expose it in front of the other students, evaluating the applicability of different strategies to each of the firms. Therefore, the feedback to each group in relation to the strategy they must present to the other students in the classroom is given before the date of the presentation. Feedback is therefore included as a key element throughout the development of the subject.

After the end of the semester (December 2014), an anonymous online survey was completed by the students to have also feedback of the satisfaction with the methodology and the process of learning. A total of 82 students were registered in this group, and 52 students filled in the questionnaire (63.41\% answer the questionnaire). Four of the questions were related with the feedback provided by the teacher, and we present results of these questions in next section. 


\section{Results and Discussion}

In this section, descriptive results of the questionnaire are presented graphically. The four questions related to feedback the survey includes are the following:

1. Please, indicate your degree of satisfaction with the feed-back that the teacher gives you in the theoretical sessions (1 very low, 5 very high).

2. Please, indicate your degree of satisfaction with the feed-back that the teacher gives you in the practical (tutorial) sessions (1 very low, 5 very high).

3. Please indicate in which degree the feed-back that the teacher gives you in the theoretical sessions improves your motivation for the subject ( 1 a negative influence, 4 a very positive influence).

4. Please indicate in which degree the feed-back that the teacher gives you in the practical (tutorial) sessions improves your motivation for the subject ( $1 \mathrm{a}$ negative influence, 4 a very positive influence).

Descriptive results of the first and second questions are showed in graphs 1 and 2 .

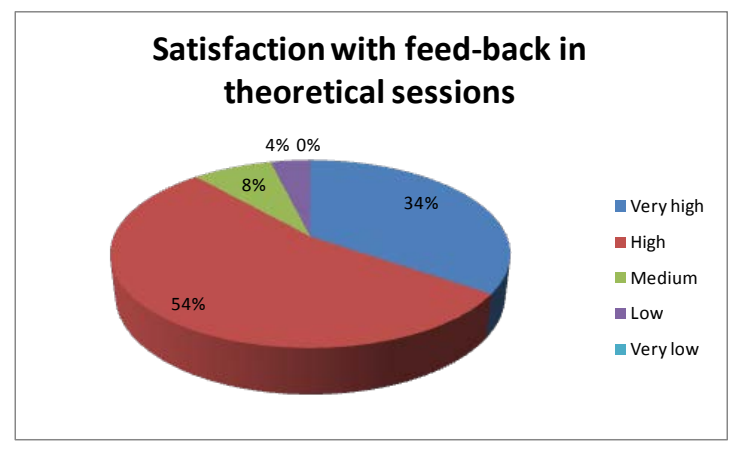

Graph 1. Degree of satisfaction with feed-back in theoretical sessions

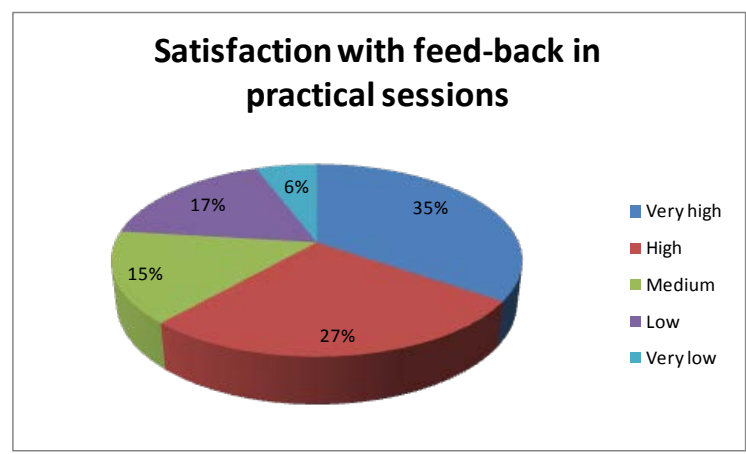

Graph 2. Degree of satisfaction with feed-back in practical sessions

The degree of satisfaction in theoretical sessions is very high or high to the $88 \%$ of the students (Graph 1), which is an important percentage. In the case of the practical sessions, the percentage of students with a high or very high satisfaction is $62 \%$ (Graph 2), which represents also a significant percentage of students that positive evaluate this feed-back.

Descriptive results of the third and fourth question are presented in the two following graphs. 


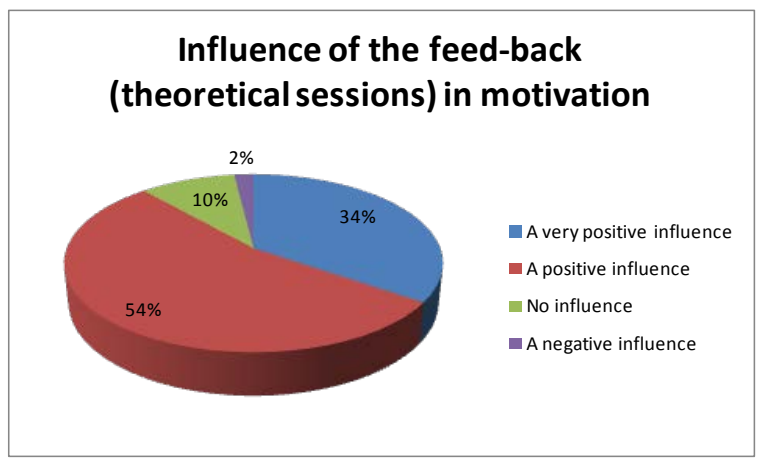

Graph 3. Influence of the feed-back of the theoretical sessions in the motivation for the subject

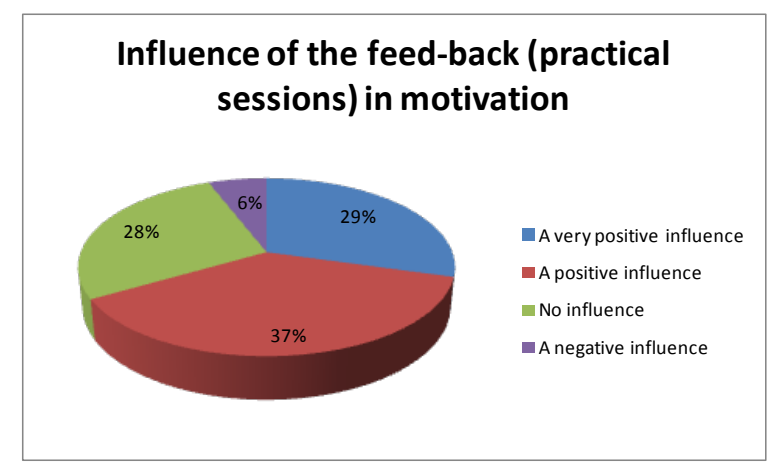

Graph 4. Influence of the feed-back of the practical sessions in the motivation for the subject

Results of the perception of the influence of the feedback on the motivation for the subject are similar as the degree of satisfaction, with an 88\% (Graph 3) of students with a positive evaluation in the case of theoretical sessions, and a percentage of $66 \%$ (Graph 2) in practical sessions. Therefore, the results are positive.

Finally, we also report academic results of the subject. Only 10 students of a total of 82 do not pass the subject and 6 have not been presented to the exam. Therefore, a percentage of $80.49 \%$ of the students passed the subject, which is a high percentage.

Although we cannot extract conclusions and causality from this descriptive data, the development of the learning process has been very satisfactory from the point of view of the teacher, and the inclusion of the feedback is one of the activities that improve the learning process.

\section{Conclusions}

Assessment feedback is an important tool to improve the learning process in high education. The role of teacher in guiding this process is stressed with this type of initiatives. In many subjects related with social sciences, as in the case of strategic management subject, there are not deterministic solutions to problems. Management in organizations requires different skills, knowledge and capabilities to deal with different complex situations. In the course, the importance of social factors, the high diversity of the firms, the influence of different variables, should be highlighted. In this learning context, the process of achieving a solution is more relevant the than the final result. Assessment feedback is necessary in the learning process in the management area. 
Preliminary results of this project, carried out in a subject of strategic management in the degree of Business Administration, show how the learning process is improved from the students' point of view. Also, this perception is confirmed by the good marks that the students achieved in the subject.

Limitations of the study are related to the descriptive nature of the data presented. Results could only be explained from a qualitative point of view and causality could not be tested. Future studies should also control from other variables that may have an influence in the results, by comparing, for example, with other groups of students.

\section{References}

Draper, S.W. (2009). What are learners actually regulating when given feedback? British Journal of Educational Technology, 40, 306-315.

Evans, C. (2013). Making sense of assessment feedback in Higher Education. Review of Educational Research, 83(1), 70-120.

Hattie, J., \& Timperley, H. (2007). The power of feedback. Review of Educational Research, 77, 81-112.

Lizzio, A., \& Wilson, K. (2008). Feedback on assessment: students' perceptions of quality and effectiveness. Assessment and Evaluation in Higher Education, 33, 263-275.

Nelson, M. M., \& Schunn, C. D. (2009). The nature of feedback: How different types of peer feedback affect writing performance. Instructional Science, 37, 375-401.

Slavin, R. E. (1990). Cooperative learning. Theory, research and practice. Needham Heights, MA: Allyn and Bacon.

Wiliam, D. (2011). What is assessment for learning? Studies in Educational Evaluation, 37, 3-14. 